\title{
Study of Different Climate and Boundary Conditions on Hygro- Thermal Properties of Timber-Framed Envelope
}

\author{
Filip Fedorik $^{1}$ Raimo Hannila ${ }^{2}$ Antti Haapala ${ }^{3}$ \\ ${ }^{1,2}$ Structural Engineering and Construction Technology \\ University of Oulu, Finland, ffilip.fedorik, raimo.hannila\} doulu.fi \\ ${ }^{3}$ Wood Materials Science, University of Eastern Finland \\ Joensuu, Finland, antti.hapala@uef. fi
}

\begin{abstract}
The present paper deals with a study of different climate effects and defining boundary conditions on mould growth risk inside building envelope. The case structure represents a common envelope of timber-framed singlefamily house. Weather conditions from Utsjoki, Oulu and Joensuu are considered in the analysis representing climate gradients wet and dry, coastal and inland conditions during a period of 6 years.

Mould growth initiation and progression require a sufficiently high humidity at suitable temperature range. Coastal regions characteristically have humid and warm climate that causes higher risk for mould growth than the more dry inland locations. The most unfavorable conditions for mould growth were seen in the coldest and the northernmost location. Hygro-thermal simulation also presented significant differences in key interior boundary conditions that, considering standard approach, may be interpreted as potential structural health issues.
\end{abstract}

Keywords: hygro-thermal simulation, mould growth risk assessment, climate effect, structural health

\section{Introduction}

The recent studies in sustainability, energy use and health of buildings show a trend towards low-energy housing solutions and material development that supports energy conservation. The industry tries to create a space for the creativity of designers in designs while ensuring low total energy use, energy harvesting options and low level of heating energy losses. Although indoor designs and visible surfaces are often highlighted in house designs, characteristics of climate conditions inside the structural elements should not be forgotten, even if they are hidden from the residents.

Current structures tend to be highly insulated causing a significant gradient in the hygro-thermal conditions inside the multi-layer building components (Fedorik et $a l, 2015)$. A certain combination of temperature and humidity exposure leads to favorable conditions for mould growth (Hukka et al, 1999; Viitanen et al, 2007; Viitanen et al, 2010) and the existence of mould spores may cause allergic reactions (Mundarri and Fisk, 2007). The presence of mould and fungi significantly influence material properties and in long run may cause structural deterioration and costly rebuilds. This is a problem especially in cases when moisture is enclosed to envelope in building stages and the insulated wall is unable to balance it with outdoor or indoor conditions.

The presence and impact of e.g. moulds in workplaces, schools and houses has become a widely discussed issue during the recent decades. The mould issue in this context was initially found in historic buildings, where indoor ventilation was not provided or it was very inefficient (Pirinen 2011). While improved ventilation and air-exchange may indeed significantly affect the indoor conditions and protect interior wallsurfaces from the mould growth, the multi-layered envelope and/or foundation and roofs may still be under a risk of mould growth. Insufficient knowledge of designers and house owners further increase the risk of unsuitable design and maintenance issues.

There are three ways to analyses house designs for their hygro-thermal properties prior to the build-up stage: lab-tests, on-site measurements and numerical simulation. Although numerical simulation is not as accurate as the other methods, its advantage consists especially of timesaving and low expenses. If suitable verification is done, simulation is helpful in predicting the risk factors against moulds (Woloszyn and Rode, 2008).

\section{Objectives}

The aim of the this study consists of finding the differences in hygro-thermal conditions inside an envelope element and defining key differences in mould index (mould growth probability indicator) depending on the defined outdoor and indoor climate conditions. Data defining outdoor boundary conditions were obtained from official weather stations located in Joensuu, Utsjoki and Oulu for a 6-year period (20092015, see Figure 1). The indoor boundary conditions were taken as multiplication of 1-year data measured in a corresponding family house and, for comparison, data 
according EN ISO 13788:2012 dependent on actual exterior conditions.

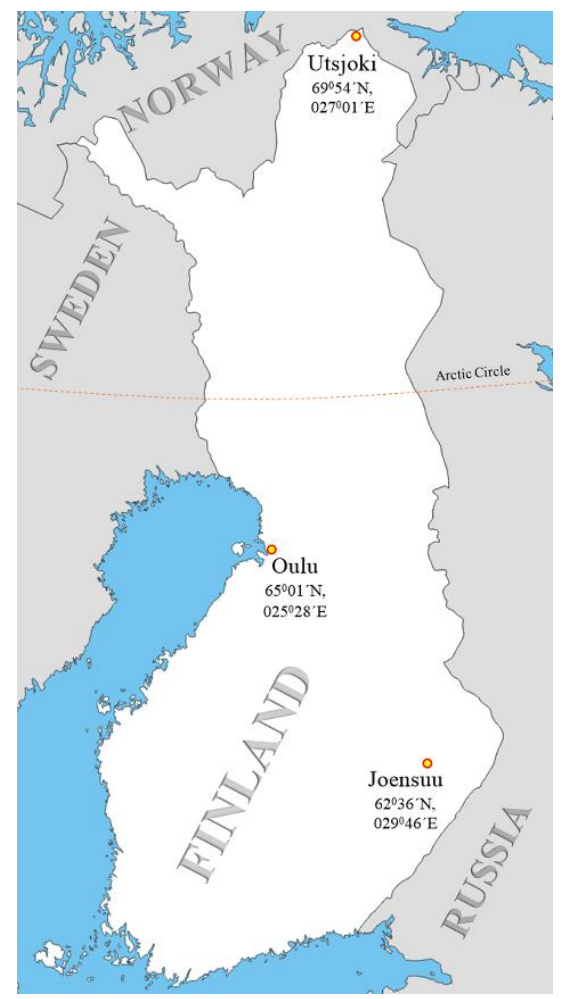

Figure 1. Localization of analyzed weather stations.

\section{Applied Methodology}

Temperature and humidity during the exposure time are the major factors driving the mould growth. Mould growth risk simulation is based on the model developed by the Tampere University of Technology and Technical Research Centre of Finland (VTT). $\mathrm{RH}_{\text {crit }}$ determines the limits between favorable and unfavorable conditions, in temperature range from 0 to $50^{\circ} \mathrm{C}$. The minimum humidity for a mould spore to start growing depends on material sensitivity, being here 80 or $85 \%$ (Ojanen et al, 2011). In the case the hygrothermal conditions are favorable, the mould growth risk increases. Otherwise, if the conditions are unfavorable for mould growth initiation, the risk decreases depending on the exposed time for unfavorable conditions.

The risk of mould growth is analyzed using a mould index value (MI, $M_{\text {index }}$ ), which is expressed by an empirical model that is based on the variables of temperature, relative humidity and exposure time, as shown in our recent study (Fedorik et al, 2015). A border between favorable and unfavorable conditions for mould-growth initiation is defined by critical relative humidity $\left(\mathrm{RH}_{\text {crit }}\right)$.

The $\mathrm{RH}_{\text {crit }}$ varies with regard to the sensitivity of material (Ojanen et al, 2011), where examples and classification of materials applied in the research is specified in Table 1. The equation is valid for material sensitivity classes 1 and 2 . In the case of classes 3 and 4 , the minimal RHcrit must be at least $85 \%$, which is the degree of humidity required for initiation of mould growth on a surface of this type of material.

The numerical hygro-thermal simulation was performed by Wufi®2D (Sedlbauer et al, 2001; Künzel, 1995), where two-dimensional model of the presented wall-envelope was created. Wufi applies twodimensional heat and moisture transfer by the governing transport equations, while drivers for the heat and moisture transfer are vapor pressure and moisture content.

\section{Analyzed Structure}

The studied structure represents a common Finnish single-family timber-framed wall element. The geometry consists in gypsum board layer installed on the interior surface, $50 \mathrm{~mm}$ continuous mineral wool, $200 \mathrm{~mm}$ mineral wool filling the timber-frame, windproof board, $32 \mathrm{~mm}$ air-gap and $23 \mathrm{~mm}$ exterior cladding made of painted wood panels (Figure 2).

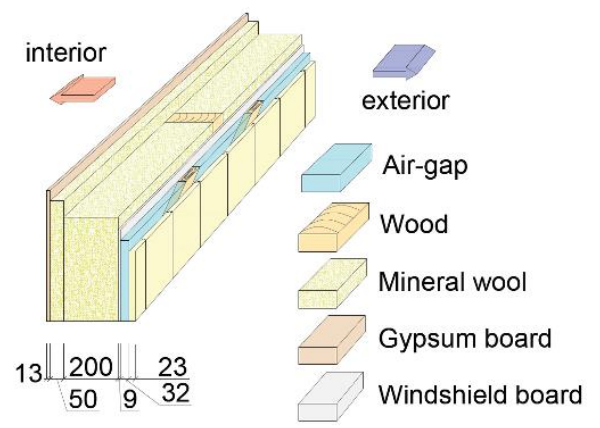

Figure 2. Schematic of the studied wall element structure.

The numerical model represents a horizontal cut-off plane of the structure (Figure 3). The hygro-thermal data was collected from 9 points (in red) considered as the most important, where humidity can creep into the structure. The geometry of the numerical model and localization of the analyzed points are given in the Figure 3. Material properties of each element are considered as they are defined in Wufiß2D material library.
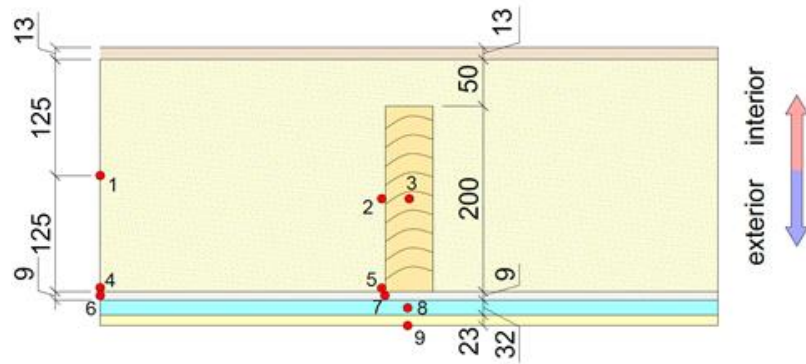

Figure 3. Analyzed points 1-9 within the wall structure. 


\section{Boundary Conditions}

The presented study applies exterior weather conditions from three different cities across Finland. The conditions from a typical coastal, inland and northern city were applied (Figure 1). The northernmost city Utsjoki in Finland is characteristic by dry and cold weather, Oulu for its humid conditions and Joensuu represents conditions for common Finnish inland city where the climate is more warm and dry. The climate data was recorded in these cities by Finnish Meteorological Institute's weather stations for 6 years from 1.4.2009 to 31.3.2015. The weather conditions in 2010 for the cities are shown in the Figure 4 (Temperature) and Figure 5 (relative humidity. RH). The time step applied in the presented study is 1 hour.

The house interior data was considered from two perspectives. At first, as defined according to EN ISO 13788:2012 considering humidity class 3 and constant indoor temperature (at $20{ }^{\circ} \mathrm{C}$ ). Secondly, actual indoor boundary conditions were measured during one year (2010) in a family house located in Oulu/Finland. These were considered to remain the same every year for the whole 6 years period.

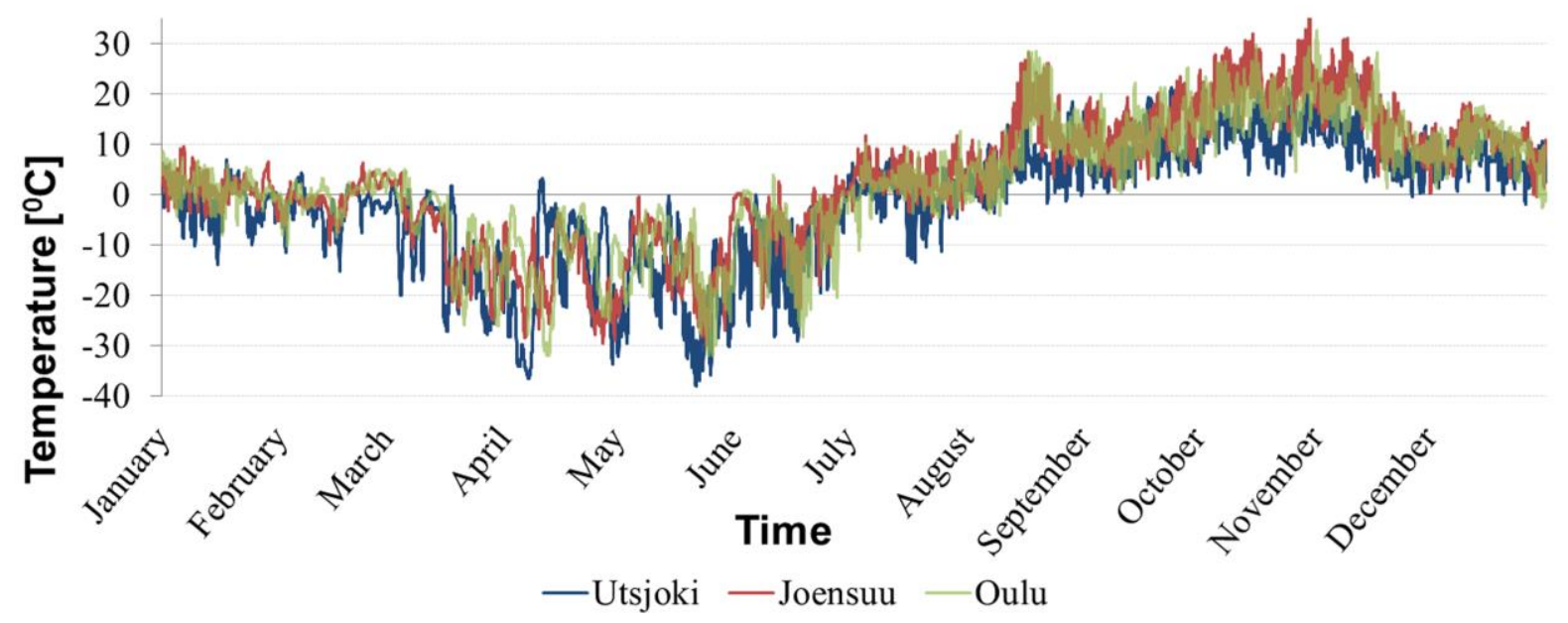

Figure 4. Development of annual temperature in 2010.

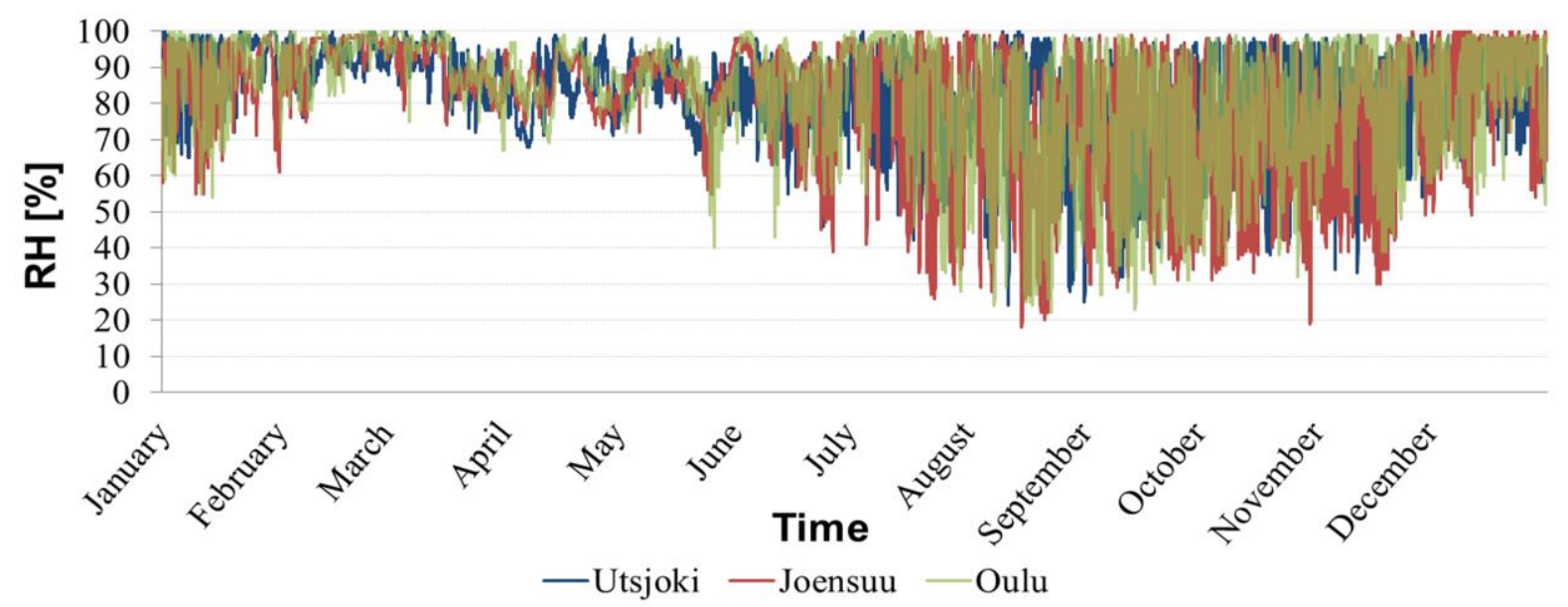

Figure 5. Development of annual humidity in 2010.

\section{Results and Discussion}

The presented study analyses the effect of different boundary conditions on mould growth risk inside an envelope of a common Finnish family house. The achieved results do not represent any major risk for the structure from the mould index point of view, although the differences between different cities vary significantly. 
The evaluated mould index achieves quite low values, representing no or very subtle mould existence according to (Ojanen et al, 2011). On the other hand, significant differences were achieved in number of favorable conditions between the analyzed cities. The favorable conditions behind a possibility of mould growth initiation should be considered in house design.

Graphical illustration of favorable and unfavorable conditions for mould growth obtained at point 5 , located between insulation and wind-proof board near the exterior wall-surface, are shown in Figures 6 to 8. The dots in the figures represent conditions of temperature and humidity achieved at each time-step of the solution, where the red dots represent conditions favorable for mould growth and blue unfavorable. It must be noted that the red dots do not mean initiation of mould, but they indicate the favorable conditions where growth can take place. Important part for mould starting to grow is the exposure time.

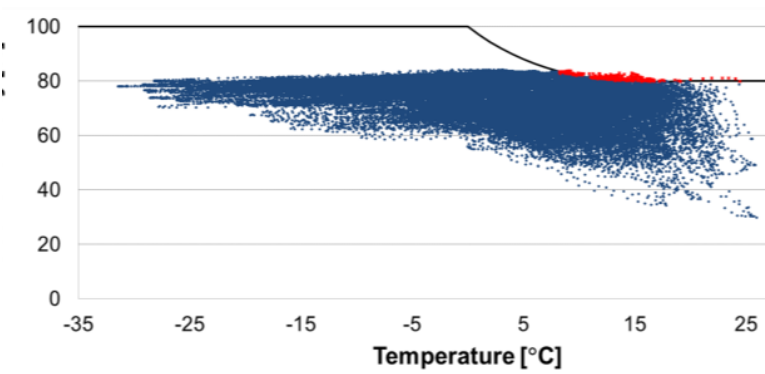

Figure 6. Favorable conditions for mould growth at exterior corner of timber-stud (point 5 in Figure 3 ) in Utsjoki.

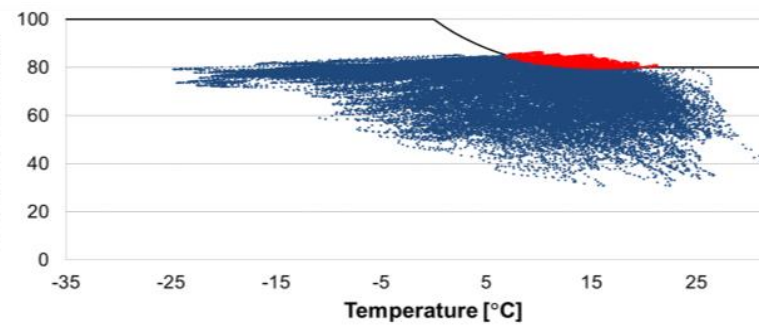

Figure 7. Favorable conditions for mould growth at exterior corner of timber-stud (point 5 in Figure 3) in Joensuu.

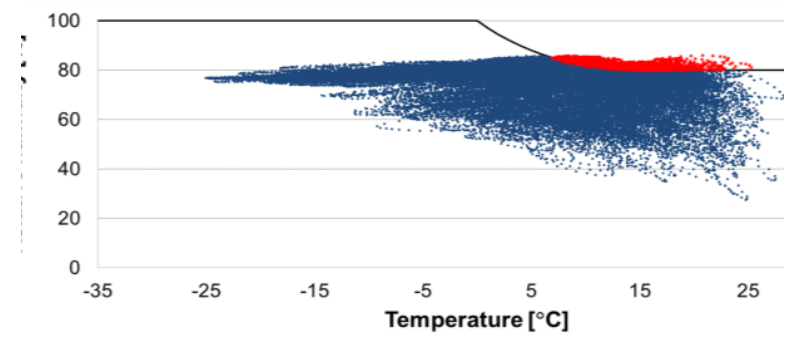

Figure 8. Favorable conditions for mould growth at exterior corner of timber-stud (point 5 in Figure 3) in Oulu.
It can be seen that the weather conditions in Utsjoki cause only briefly the conditions for favorable environment for mould growth compared to conditions in Joensuu and especially in Oulu. The evaluated maximum mould index achieved and percentage period when the structure is exposed to favorable conditions for mould growth at each of the analyzed points considering measured interior boundary conditions are summarized in the Table 1 , where points 1 to 3 are not included as far as the mould index was always 0 .

Table 1. $\mathrm{M}_{\text {index }}$ and Favourable Conditions Considering the Measured Interior Conditions.

\begin{tabular}{|c|c|c|c|c|c|c|}
\hline \multirow{2}{*}{$\begin{array}{l}\text { Analysi } \\
\text { s point }\end{array}$} & \multicolumn{2}{|c|}{ Joensuu } & \multicolumn{2}{|c|}{ Oulu } & \multicolumn{2}{|c|}{ Utsjoki } \\
\hline & $\begin{array}{c}\max _{\text {Minde }} \\
\quad x \\
\end{array}$ & $\begin{array}{c}F_{\text {cond }} \\
{[\%]}\end{array}$ & $\begin{array}{c}\max \\
M_{\text {inde }} \\
\quad x \\
\end{array}$ & $\begin{array}{c}F_{\text {cond }} \\
{[\%]}\end{array}$ & $\begin{array}{c}\max \\
M_{\text {inde }} \\
x \\
\end{array}$ & $\begin{array}{c}F_{\text {cond }} \\
{[\%]}\end{array}$ \\
\hline 4 & 0.01 & 6.16 & 0.01 & 6.70 & 0.01 & 1.93 \\
\hline 5 & 0.14 & 4.35 & 0.18 & 5.49 & 0.02 & 0.58 \\
\hline 6 & 0.01 & 6.76 & 0.02 & 7.44 & 0.01 & 2.23 \\
\hline 7 & 0.16 & 4.77 & 0.17 & 6.06 & 0.02 & 0.91 \\
\hline 8 & 0.40 & 15.34 & 0.67 & 18.24 & 0.14 & 7.14 \\
\hline 9 & 5.96 & 26.42 & 5.99 & 29.99 & 5.59 & 16.67 \\
\hline
\end{tabular}

In the case of applying interior boundary conditions according to EN ISO 13788:2012, the favorable environment for mould growth and evaluated mould growth risk values are slightly bigger. It means that according to presented study, the applied measured interior conditions ensure healthier conditions for the structure although in both cases the mould index represents no mould growth during the analyzed period at all inner points. The summary of the favorable conditions and maximal value of mould growth risk achieved during the analyzed period is given in the Table 2. 
Table 2. $\mathrm{M}_{\text {index }}$ and Favourable Conditions Considering Standardized Interior Conditions.

\begin{tabular}{|c|c|l|l|l|l|l|}
\hline \multirow{2}{*}{$\begin{array}{c}\text { Analysi } \\
\text { s point }\end{array}$} & \multicolumn{2}{|c|}{ Joensuu } & \multicolumn{2}{c|}{ Oulu } & \multicolumn{2}{c|}{ Utsjoki } \\
\cline { 2 - 7 } & $\begin{array}{c}\boldsymbol{M}_{\text {inde }} \\
\boldsymbol{x}\end{array}$ & $\begin{array}{c}\boldsymbol{F}_{\text {cond }} \\
{[\%]}\end{array}$ & $\begin{array}{c}\boldsymbol{m a x}_{\boldsymbol{M}} \\
\boldsymbol{M}_{\text {inde }} \\
\boldsymbol{x}\end{array}$ & $\begin{array}{c}\boldsymbol{F}_{\text {cond }} \\
{[\%]}\end{array}$ & $\begin{array}{c}\text { max } \\
\boldsymbol{M}_{\text {inde }} \\
\boldsymbol{x}\end{array}$ & $\begin{array}{c}\boldsymbol{F}_{\text {cond }} \\
{[\%]}\end{array}$ \\
\hline 4 & 0.02 & 11.07 & 0.03 & 13.43 & 0.01 & 3.56 \\
\hline 5 & 0.27 & 7.01 & 0.39 & 9.79 & 0.03 & 1.58 \\
\hline 6 & 0.02 & 10.92 & 0.03 & 13.17 & 0.01 & 3.59 \\
\hline 7 & 0.22 & 6.12 & 0.29 & 8.26 & 0.03 & 1.40 \\
\hline 8 & 0.45 & 15.75 & 0.75 & 18.76 & 0.14 & 7.38 \\
\hline 9 & 5.96 & 26.42 & 5.99 & 29.99 & 5.59 & 16.67 \\
\hline
\end{tabular}

The highest mould index value was found on the exterior surface of the envelope. A development of mould index at point 8 , located in the exterior air-gap between wind-proof board and exterior cladding are illustrated in the Figure 9.

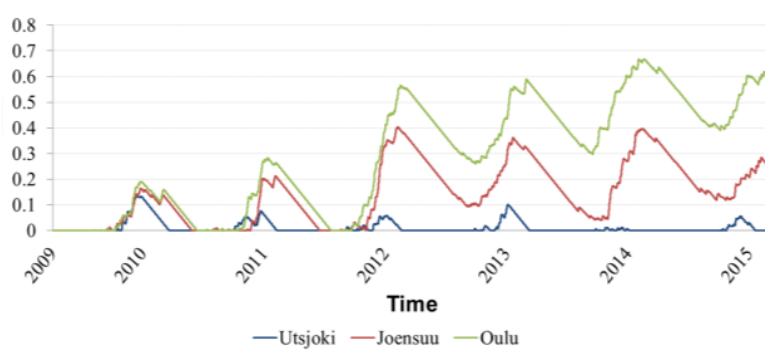

Figure 9. $\mathrm{M}_{\text {index }}$ in air-gap between the gypsum-board and exterior cladding (point 8 in Figure 3).

The highest mould index value was achieved on the exterior surface of the envelope. Differences in mould index development on the exterior surface of the envelope for the analyzed cities are figured in the Figure 10. At this point, notable differences in climatic variation can be seen. The humid climate in Oulu causes steeper developing of the mould index than Joensuu and Utsjoki climate. The lowest mould index is achieved in Utsjoki. It seems that for this 6-year period of analysis the houses built in all three locations are able to dry once wetted and the periods of high humidity are insufficient to cause significant issues. The ability of wall structure to dry once wetted is therefore critical to prevent significant problems and mould growth, as shown in our previous study (Fedorik et al, 2015).

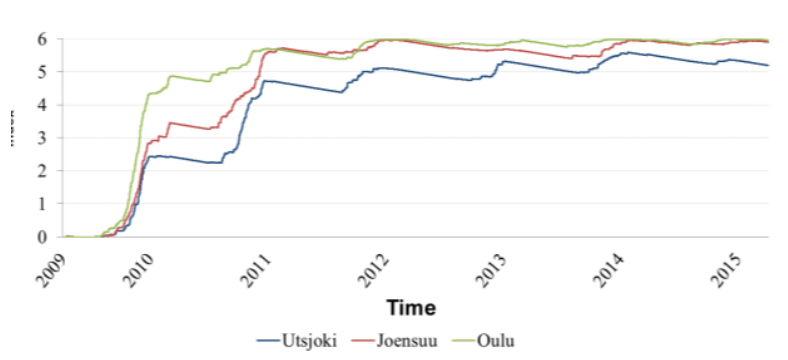

Figure 10. $\mathrm{M}_{\text {index }}$ on the exterior surface of envelope (point 9 in Figure 3).

\section{Conclusions}

The presented study presents analysis of climate effect on mould growth risk inside an envelope of timberframed family house. As expected, the worst conditions for house health are achieved in coastal city of Oulu that has characteristically humid climate. The best results were found on climate located in the northernmost city of Finland Utsjoki, where low humidity and temperature cause unfavorable conditions for mould growth initiation.

Significant difference in numerical simulation of hygro-thermal conditions of buildings is made by defining the relevant boundary conditions. In addition, applying measured or standardized interior boundary conditions lead to different results, although none of them represents a danger of serious mould growth in the analyzed case. On the other hand, if more sensitive materials would be used, mould growth in a structure in humid environment may occur. Using one set of conditions to analyze a standard structure is likely to lead into misjudgment of the structural health if the actual location of the house is significantly different in its climate conditions.

\section{References}

F. Fedorik, M. Malaska, R. Hannila, and A. Haapala. Improving the thermal performance of concrete-sandwich envelopes in relation to the moisture behaviour of building structures in boreal conditions. Energy and Buildings, 107: 226-233, 2015.

A. Hukka and H. A. Viitanen. A mathematical model of mould growth on wooden material, Wood Science and Technology 33(6): 475-485, 1999.

H. M. Künzel. Simultaneous heat and moisture transport in building components. Fraunhofer Institute of Building Physics, Germany, 1995.

D. Mudarri and W. J. Fisk. Public health and economic impact of dampness and mold, Indoor Air Journal, 17: 226-235, 2007.

T. Ojanen, R. Peuhkuri, H. Viitanen, K. Lähdesmäki, J. Vinha, and K. Salminen. Classification of material sensitivity - New approach for mould growth modelling. 9th Nordic Symposium on Building Physics, 29 May - 2 June 2011, Tampere, Finland. 
J. Pirinen. Building inspections in Finland - Fighting against the moulds, moisture and mould programme. 9th Nordic Symposium on Building Physics, 29 May - 2 June 2011, Tampere, Finland.

K. Sedlbauer, M. Krus, W. Zilling, and H. M. Künzel. Mold growth prediction by computational simulation. ASHRAE Conference, IAQ, San Francisco, CA, 4-7 November

2001.

H. A. Viitanen and T. Ojanen. Improved model to predict mold growth in building materials. Report based on the VTT projects "Building Biology" and "Integrated Prevention of Moisture and Mould Problems", 2007, Finland.

H. Viitanen, J. Vinha, K. Salminen, T. Ojanen, R. Peuhkuri, L. Paajanen, and K. Lähdesmäki. Moisture and bio-deterioration risk of building materials and structures. Journal of Building Physics, 33(3): 201-224, 2010.

M. Woloszyn and C. Rode. Tools for performance simulation of heat, air and moisture conditions of whole buildings. Building Simulation, 1(1): 5-24, 2008. 